\title{
Knockdown of IncRNA ANRIL inhibits the development of cisplatin resistance by upregulating miR-98 in lung cancer cells
}

\author{
XI WANG, GUOJUN ZHANG, ZHE CHENG, LINGLING DAI, LIUQUN JIA, XIAOGANG JING, \\ HUAN WANG, RUI ZHANG, MENG LIU, TIANCI JIANG, YUANJIAN YANG and MENG YANG
}

Department of Respiration, The First Affiliated Hospital of Zhengzhou University, Zhengzhou, Henan 450052, P.R. China

Received October 29, 2019; Accepted June 2, 2020

DOI: $10.3892 /$ or.2020.7685

\begin{abstract}
Emerging evidence has demonstrated that abnormally expressed long non-coding (lnc) RNAs contribute to drug resistance in various types of malignancy. LncRNA antisense non-coding RNA in the inhibitor of cyclin-dependent kinase 4 locus (ANRIL) exerts oncogenic activity and acts as a key player in a variety of carcinomas, including non-small cell lung cancer. The present study aimed to investigate the functional roles of ANRIL in cisplatin (DDP) resistance of lung cancer and the underlying mechanism involved in the competing endogenous RNA regulatory network. The expression levels of ANRIL and microRNA (miR)-98 in lung cancer tissues and DDP-resistant lung cancer cells were assessed by reverse transcription-quantitative (RT-q) PCR. The Pearson's correlation coefficient was used to determine the correlation between the expression levels of ANRIL and miR-98 in lung cancer tissues. Cell proliferation and apoptosis were detected by MTT assay and flow cytometry analysis, respectively. The expression levels of proliferation- and apoptosis-associated proteins were detected by western blot analysis. The potential interaction between ANRIL and miR-98 was confirmed by RNA immunoprecipitation (RIP), dual luciferase reporter assay and RT-qPCR. The results of the present study demonstrated that ANRIL was upregulated and miR-98 was downregulated in lung cancer tissues and A549/DDP cells. In addition, the Pearson's correlation analysis revealed that the expression of ANRIL was significantly negatively correlated with that of miR-98 in lung cancer tissues. ANRIL overexpression reversed the DDP-induced cell proliferation suppression and apoptosis in lung cancer cells, whereas ANRIL knockdown exhibited the opposite effects. RIP, dual luciferase reporter assay and RT-qPCR analysis results demonstrated that ANRIL directly interacted with miR-98 and suppressed miR-98 expression.
\end{abstract}

Correspondence to: Professor Zhe Cheng, Department of Respiration, The First Affiliated Hospital of Zhengzhou University, 1 Jianshe East Road, Zhengzhou, Henan 450052, P.R. China E-mail: chengzhecz001@163.com

Key words: long non-coding RNA ANRIL, cisplatin resistance, microRNA-98, lung cancer
Furthermore, transfection with the miR-98 mimics promoted DDP-induced cell proliferation inhibition and apoptosis in lung cancer cells, and these effects were partially reversed by ANRIL overexpression. In conclusion, ANRIL knockdown inhibited the development of DDP resistance by upregulating miR-98, providing novel insights into the molecular mechanism of ANRIL involvement in DDP resistance of lung cancer cells.

\section{Introduction}

Lung cancer, predominantly non-small-cell lung cancer (NSCLC), is one of the most common types of malignant cancer and the primary cause of tumor-associated mortality and morbidity worldwide with a high incidence rate and a 5-year survival rate of $18 \%$ (1). Platinum-based chemotherapy regimens are currently the standard adjuvant treatment strategy for advanced NSCLC following surgical resection (2). As a widely used platinum-coordinated complex in cancer therapy, cisplatin (DDP) is the first-line chemotherapeutic drug against NSCLC due to its therapeutic advantages such as high efficiency and mild side effects (3). However, the development of drug resistance, which limits the clinical therapeutic efficacy of DDP, is currently a major impediment to successful chemotherapy $(2,4)$. The mechanisms underlying DDP resistance are extremely complex and multi-factorial (5). Therefore, elucidating these molecular mechanisms is clinically important to develop therapeutic approaches for the treatment of lung cancer and to improve the therapeutic efficacy of lung cancer chemotherapy.

Human genome sequence data indicates that only $2 \%$ of the genome encodes proteins, and the majority of genes are transcribed into non-coding RNAs (ncRNAs) (6,7). Among the various types of ncRNAs, long ncRNAs (lncRNAs) are defined as non-protein coding RNA transcripts that are $>200$ nucleotides long (8). LncRNAs serve regulatory roles in gene expression at the transcriptional, post-transcriptional and epigenetic levels, and thus are implicated in a range of physiological and pathological processes, including the pathogenesis and development of tumors (9). A previous study has demonstrated that upregulation of lncRNA HOX transcript antisense RNA (HOTAIR) may repress the chemosensitivity of lung cancer cells resistant to cisplatin (8). Antisense ncRNA in the inhibitor of cyclin-dependent kinase 4 (INK4) locus 
(ANRIL), also termed CDKN2B antisense RNA1, is transcribed as a $3.8-\mathrm{kb} \operatorname{lncRNA}$ in the antisense orientation of the INK4B-ARF-INK4A gene cluster at chromosome 9p21 (10). A number of studies have demonstrated that ANRIL is aberrantly upregulated in several types of malignancy, such as lung, breast and gastric cancer (11-13). Accumulating evidence has suggested that ANRIL exhibits oncogenic activity and acts as a key player in a variety of carcinomas, including NSCLC $(11,12,14)$. However, the detailed roles of ANRIL in DDP resistance of lung cancer and the underlying mechanisms remain to be elucidated.

microRNAs (miRNAs) are a superfamily of small ncRNAs that are 19-25 nucleotides long and serve important roles in the regulation of gene expression at the post-transcriptional level by binding to the 3' untranslated region (UTR) of the target mRNA, resulting in mRNA degradation or translation repression (15). An increasing number of studies have reported that miRNAs participate in the regulation of various biological processes, such as cell proliferation, invasion and apoptosis $(16,17)$. In addition, dysregulation of miRNA expression has been revealed to be involved in the chemoresistance of various types of cancer, including NSCLC $(18,19)$. Specifically, miR-98 has been demonstrated to be downregulated in DDP-resistant NSCLC cells, and high expression of miR-98 leads to high sensitivity to DDP (20). A novel regulatory mechanism regarding the competing endogenous (ce) RNA hypothesis has suggested that lncRNAs can act as miRNA sponges via competition for shared miRNA-response elements to suppress the expression and activity of miRNAs (21). Therefore, the present study focused on the interaction between NARIL and miR-98 in lung cancer.

The present study aimed to investigate the functional roles of ANRIL in DDP resistance of lung cancer and the underlying mechanism involved in the ceRNA regulatory network.

\section{Materials and methods}

Tissue sample collection. A total of 26 NSCLC tissues and paired adjacent normal lung tissues from patients (mean age, 58 years; age range, $40-72$ years) undergoing resection were collected from the First Affiliated Hospital of Zhengzhou University (Zhengzhou, China), between January 2017 and December 2018. The patients received no preoperative chemotherapy or radiotherapy and were diagnosed with NSCLC by histopathological evaluation. The distance between cancerous lesions and adjacent healthy tissues was $\geq 5 \mathrm{~cm}$. All tissue specimens were immediately frozen in liquid nitrogen and stored at $-80^{\circ} \mathrm{C}$ until RNA extraction. The present study was reviewed and approved by the Research Ethics Committee of the First Affiliated Hospital of Zhengzhou University. Written consent was obtained from all patients. The clinicopathological characteristics of the patients with NSCLC are list in Table I.

Cell culture and transfection. Normal lung epithelial cells (BEAS-2B) were obtained from the American Type Culture Collection. The human lung adenocarcinoma cell line A549 and DDP-resistant A549/DDP cells were purchased from Nanjing Keygen Biotechnology Co. Ltd. All cells were cultured in RPMI-1640 medium (Invitrogen; Thermo Fisher Scientific, Inc.) supplemented with $10 \%$ fetal bovine serum (FBS; Gibco;
Thermo Fisher Scientific, Inc.), $1 \%$ L-glutamine and $1 \%$ penicillin/streptomycin (Invitrogen; Thermo Fisher Scientific, Inc.) at $37^{\circ} \mathrm{C}$ in a humidified atmosphere with $5 \% \mathrm{CO}_{2}$. A549/DDP cells were cultured in RPMI-1640 medium containing $1 \mu \mathrm{g} / \mathrm{ml}$ DDP (Sigma Aldrich; Merck KGaA) to maintain the resistance of this cell line to DDP prior to the experiments. Cells in the logarithmic growth phase were used for the experiments.

pcDNA-ANRIL, pcDNA vector (vector), small interfering (si) RNAs targeting ANRIL (si-ANRIL-1, si-ANRIL-2 and si-ANRIL-3), scrambled non-targeting siRNA negative control (si-NC), miR-98 mimics (miR-98) and scrambled non-targeting miRNA negative control (miR-NC) were purchased from Shanghai Genepharma Co., Ltd. The sequences of si-ANRIL and miR-98 mimics were as follows: si-ANRIL-1, 5'-ACAGAA UAGUGUUCUUCUGCU-3'; si-ANRIL-2, 5'-UUUCUAAUA AUUCCAUUUGUC-3'; si-ANRIL-3, 5'-UCUGUUUAAAUU AUGAAUGUG-3'; si-NC, 5'-TTCTCCGAACGTGTCACGT-3'; miR-98 mimics, 5'-UGAGGUAGUAAGUUGUAUUGUU-3'; and miR-NC, 5'-UAAAGUGCUUAUAGUGCAGGUAG-3'. A549 and A549/DDP cells were seeded in 6-well plates at a density of $1 \times 10^{5}$ cells/well and grown to $70 \%$ confluence prior to transfection. According to manufacturer's instructions, cells were transfected with oligonucleotides $(40 \mathrm{nM})$ or plasmids $(2 \mu \mathrm{g} / \mathrm{ml})$ using Lipofectamine ${ }^{\circledR} 2000$ transfection reagent (Invitrogen; Thermo Fisher Scientific, Inc.) at room temperature, and the transfected cells were cultured for the indicted times at $37^{\circ} \mathrm{C}$ in a humidified atmosphere with $5 \% \mathrm{CO}_{2}$.

Reverse transcription-quantitative PCR (RT-qPCR). Total RNA was extracted from tissues and cultured cells using TRIzol ${ }^{\circledR}$ reagent (Invitrogen; Thermo Fisher Scientific, Inc.). The first strand of complementary DNA (cDNA) was synthesized from $\sim 1 \mu \mathrm{g}$ of the extracted total RNA sample using the Prime-Script RT reagent kit (Takara Bio, Inc.) at $37^{\circ} \mathrm{C}$ for $15 \mathrm{~min}, 85^{\circ} \mathrm{C}$ for $5 \mathrm{sec}$ and $4^{\circ} \mathrm{C}$ until the removal of the RT products. The expression levels of ANRIL and miR-98 were quantified PCR using the TaqMan Power SYBR ${ }^{\circledR}$ Green PCR Mix (Invitrogen; Thermo Fisher Scientific, Inc.) and the SYBR ${ }^{\circledR}$ Green Master Mix (cat\#: 4444556; Thermo Fisher Scientific), respectively. The qPCR was performed using the Applied Biosystems 7500 Real-time PCR system (Applied Biosystems; Thermo Fisher Scientific, Inc.) under the following thermocycling conditions: $94^{\circ} \mathrm{C}$ for $2 \mathrm{~min}$; followed by 35 cycles of $94^{\circ} \mathrm{C}$ for $45 \mathrm{sec}, 56^{\circ} \mathrm{C}$ for $30 \mathrm{sec}$ and $72^{\circ} \mathrm{C}$ for $45 \mathrm{sec}$; and an extension at $72^{\circ} \mathrm{C}$ for $10 \mathrm{~min}$. The relative gene expression levels were calculated and normalized to the expression of GAPDH (for lncRNAs) or U6 small nuclear RNA (for miRNAs) using the $2^{-\Delta \Delta \mathrm{Cq}}$ method (22). The primers used in the present study are listed in Table II.

Western blot assay. Cultured A549 and A549/DDP cells were lysed using a Radio-Immunoprecipitation Assay (RIPA) protein extraction reagent (Cell Signaling Technology, Inc.) containing phenylmethanesulfonyl fluoride. The bicinchoninic acid (BCA) protein assay was performed to determine the protein concentration using a BCA assay kit (Thermo Fisher Scientific, Inc.). Protein extracts ( $\sim 30 \mu \mathrm{g} / \mathrm{lane})$ were separated by SDS-PAGE $(10 \%$ gel) and transferred to polyvinylidene difluoride membranes (EMD Millipore). The membranes were blocked with 5\% non-fat milk for $1 \mathrm{~h}$ at room temperature. The 
Table I. Clinicopathological characteristics of patients with non-small cell lung cancer.

\begin{tabular}{|c|c|c|c|c|c|}
\hline ID & Age & Sex & $\begin{array}{l}\text { TNM } \\
\text { stage }\end{array}$ & $\begin{array}{c}\text { Smoking } \\
\text { status }\end{array}$ & $\begin{array}{c}\text { Prior } \\
\text { therapy }\end{array}$ \\
\hline 1 & 64 & Male & IV & Former & Surgery \\
\hline 2 & 40 & Male & II & Current & Surgery \\
\hline 3 & 53 & Male & IV & Former & Surgery \\
\hline 4 & 56 & Male & IV & Former & None \\
\hline 5 & 46 & Male & IV & Current & None \\
\hline 6 & 49 & Male & II & Current & Surgery \\
\hline 7 & 58 & Male & IV & Current & Surgery \\
\hline 8 & 64 & Female & IV & Current & Surgery \\
\hline 9 & 63 & Female & IV & Current & Surgery \\
\hline 10 & 67 & Male & III & Current & Surgery \\
\hline 11 & 45 & Male & III & Current & None \\
\hline 12 & 43 & Male & I & Current & None \\
\hline 13 & 44 & Male & I & Current & None \\
\hline 14 & 69 & Female & IV & Former & Surgery \\
\hline 15 & 64 & Female & IV & Current & Surgery \\
\hline 16 & 63 & Male & IV & Former & Surgery \\
\hline 17 & 59 & Female & IV & Current & Surgery \\
\hline 18 & 66 & Male & II & Current & None \\
\hline 19 & 67 & Male & IV & Current & Surgery \\
\hline 20 & 54 & Female & II & Former & None \\
\hline 21 & 58 & Male & IV & Current & Surgery \\
\hline 22 & 48 & Male & II & Current & Surgery \\
\hline 23 & 72 & Male & IV & Former & Surgery \\
\hline 24 & 67 & Male & IV & Former & Surgery \\
\hline 25 & 64 & Male & IV & Former & Surgery \\
\hline 26 & 65 & Male & IV & Former & Surgery \\
\hline
\end{tabular}

TNM, Tumor-Node-Metastasis (39).

Table II. Primers used for reverse transcription-quantitative PCR.

\begin{tabular}{ll}
\hline Primer & \multicolumn{1}{c}{ Sequences $\left(5^{\prime} \rightarrow 3^{\prime}\right)$} \\
\hline U6 & F: CTCGCTTCGGCAGCACA \\
& R: AACGCTTCACGAATTTGCGT \\
miR-98 & F: TGAGGTAGTAAGTTGTAT \\
& R: AACATGTACAGTCCATGGATG \\
ANRIL & F: CTTATTTTATTCCTGGCTCCCCT \\
& R: ATCATTCTCCTCAAATTACAGAG \\
GAPDH & F: GTCAACGGATTTGGTCTGTATT \\
& R: AGTCTTCTGGGTGGCAGTGAT
\end{tabular}

ANRIL, antisense non-coding RNA in the inhibitor of cyclin-dependent kinase 4 locus; miR, microRNA; F, forward; R, reverse.

membranes were incubated with primary antibodies against Ki67 (1:1,500; cat. no. sc-23900; Santa Cruz Biotechnology, Inc.), cleaved caspase-3 (1:2,000; cat. no. 9661; Cell Signaling
Technology, Inc.), mitogen-activated protein kinase kinase (MEK; 1:1,000; cat. no. 4694; Cell Signaling Technology, Inc.), phosphorylated (p-)MEK (1:1,000; cat. no. 2338; Cell Signaling Technology, Inc.), mitogen-activated protein kinase 1/2 (ERK1/2; 1:1,000; cat. no. ab17942; Abcam), p-ERK1/2 (1:2,000; \#4370; Cell Signaling Technology) or $\beta$-actin $(1: 1,500$; cat. no. ZRB1312; Sigma-Aldrich; Merck KGaA) at $4{ }^{\circ} \mathrm{C}$ overnight. The membranes were washed twice with PBS and incubated with a horseradish peroxidase-conjugated anti-mouse IgG secondary antibody (1:1,000; cat. no. sc-2357; Santa Cruz Biotechnology, Inc.) and visualized using an ECL system (Amersham; Cytiva). The data were quantified using ImageJ software (version 1.8.0.112; National Institutes of Health).

MTT assay. A549 and A549/DDP cells $\left(2 \times 10^{3}\right)$ at the logarithmic growth phase were plated into 96-well plates at $48 \mathrm{~h}$ post-transfection and treated with or without 1 or $2 \mu \mathrm{g} / \mathrm{ml}$ DDP at $37^{\circ} \mathrm{C}$ for $0,24,48$ and $72 \mathrm{~h}$. Following treatment, $20 \mu \mathrm{l} \mathrm{MTT}$ solution ( $5 \mathrm{mg} / \mathrm{ml}$; Sigma-Aldrich; Merck KGaA) was added into each well for $4 \mathrm{~h}$ at $37^{\circ} \mathrm{C}$. Subsequently, the supernatant of each well was removed, and $150 \mu \mathrm{l}$ DMSO (Sigma-Aldrich; Merck KGaA) was added to dissolve the formazan crystal. The absorbance value at $490 \mathrm{~nm}$ was detected using a plate reader (Bio-Rad Laboratories, Inc.).

Apoptosis analysis by flow cytometry. The transfected A549 and A549/DDP cells were incubated with culture medium with or without 1 or $2 \mu \mathrm{g} / \mathrm{ml} \mathrm{DDP}$ at $37^{\circ} \mathrm{C}$ for $48 \mathrm{~h}$. For apoptosis analysis, the cells were digested using trypsin without EDTA for 1-2 min, and $1 \mathrm{ml}$ RPMI-1640 medium with $10 \%$ FBS were added to terminate the digestion. Then, the cells were centrifuged at $111 \mathrm{x} \mathrm{g}$ for $5 \mathrm{~min}$ at $4^{\circ} \mathrm{C}$ and collected. The collected cells were double-stained with a Annexin V-FITC Apoptosis Detection kit (BD Biosciences) according to the manufacturer's protocol. The apoptotic cells were analyzed using a FACScan flow cytometer (Becton, Dickinson and Company) with Cell Quest software version 7.5.3 (BD Biosciences). All experiments were repeated in triplicate.

Dual luciferase reporter assay. Prediction using bioinformatics online software miRcode (http://www.mircode.org/) and Starbase 2.0 (http://starbase.sysu.edu.cn/mirLncRNA.php) identified that miR-98 contained putative binding sites with ANRIL. The fragments of ANRIL containing the potential miR-98 binding sites were amplified and cloned into pGL3 plasmids (Promega Corporation) to produce an ANRIL-WT plasmid. The luciferase reporter plasmids containing the mutated miR-98 binding sites in ANRIL were constructed using the Quick-Change Site Directed Mutagenesis kit (Invitrogen; Thermo Fisher Scientific, Inc.) and termed ANRIL-MUT. For the luciferase reporter assay, cells transfected with $20 \mathrm{nM}$ miR-98 mimics (miR-98) and miR-NC were seeded into 96-well plates at a density of 1,000 cells/well and transfected with the vector, ANRIL-WT or ANRIL-MUT (50 ng) and the internal control Renilla luciferase plasmid using Lipofectamine ${ }^{\circledR} 2000$ transfection reagent (Invitrogen; Thermo Fisher Scientific, Inc.) at $37^{\circ} \mathrm{C}$ for $48 \mathrm{~h}$. At $48 \mathrm{~h}$ post-transient transfection, the luciferase activity was measured with a Dual-Luciferase Reporter Assay System (Promega Corporation) and normalized to Renilla luciferase activity. 

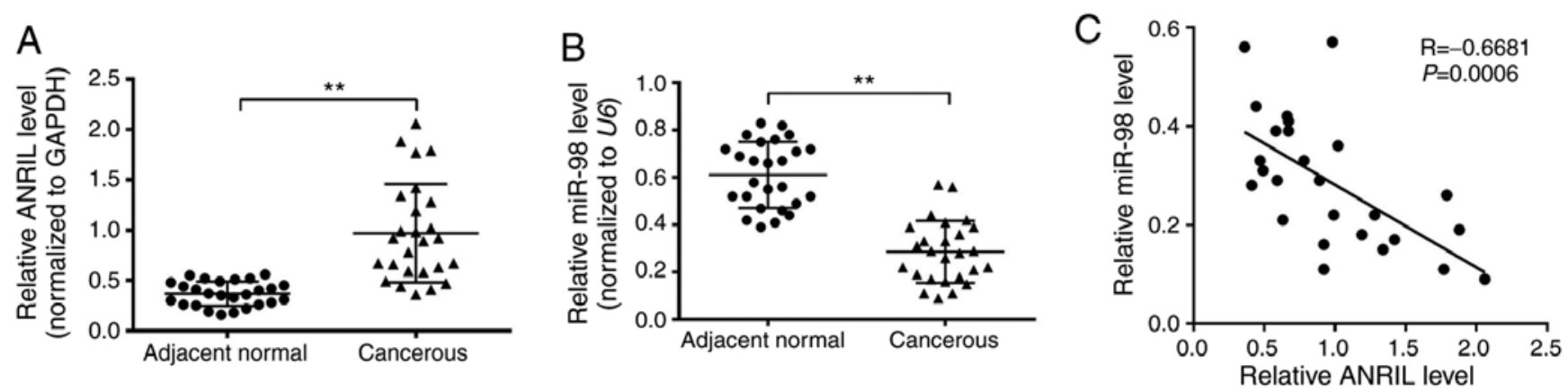

Figure 1. Expression of ANRIL and miR-98 in lung cancer tissues. Reverse transcription-quantitative PCR was used to detect the relative expression levels of (A) ANRIL and (B) miR-98 in NSCLC tissues compared with paired corresponding non-cancerous tissues from 26 patients with NSCLC. (C) Pearson's correlation analysis of ANRIL and miR-98 expression levels was conducted. ${ }^{* *} \mathrm{P}<0.01$. NSCLC, non-small cell lung cancer; ANRIL, antisense non-coding RNA in the inhibitor of cyclin-dependent kinase 4 locus; miR, microRNA.

RNA immunoprecipitation $(R I P)$. In order to confirm the association between ANRIL and miR-98, RIP assay was performed using a Magna RIP ${ }^{\text {тм }}$ RNA-Binding Protein Immunoprecipitation kit (EMD Millipore). A549 and A549/DDP cells $\left(1 \times 10^{7}\right)$ were lysed using complete RNA lysis buffer containing $1 \mathrm{mM}$ PMSF (Sigma-Aldrich; Merck KGaA), 1 mM DTT (Invitrogen; Thermo Fisher Scientific, Inc.), $1 \%$ protease inhibitor (Sigma-Aldrich; Merck KGaA) and $200 \mathrm{U} / \mathrm{ml}$ RNase inhibitor. Then, $100 \mu \mathrm{l}$ whole cell lysis solution was co-incubated with the RIP buffer containing $A+G$ magnetic beads conjugated with $8 \mu \mathrm{g}$ anti-human argonaute 2 (Ago2) antibody (1:40; cat. no. ab186733; Abcam) and normal mouse IgG (1:30; cat. no. AP503P; EMD Millipore) as a negative control. To avoid non-specific binding, the samples were incubated with $10 \mathrm{mg} / \mathrm{ml}$ Proteinase $\mathrm{K}$, and the immunoprecipitated RNA was isolated using TRIzol ${ }^{\circledR}$ reagent (Invitrogen; Thermo Fisher Scientific, Inc.). Co-precipitated RNAs were subjected to RT-qPCR analysis as aforementioned.

Statistical analysis. Data are presented as the mean \pm standard deviation (SD). All experiments were repeated separately at least three times. Statistical analysis was performed using SPSS 13.0 (SPSS, Inc.). Differences among three or more groups were analyzed by one-way analysis of variance with Tukey's post hoc test. Correlation analysis was performed by Pearson's correlation test. Significant differences between two groups were estimated by unpaired and paired two-tailed Student's t-test. $\mathrm{P}<0.05$ was considered to indicate a statistically significant difference.

\section{Results}

ANRIL is upregulated and miR-98 is downregulated in lung cancer compared with healthy tissues. In order to investigate whether the expression levels of ANRIL and miR-98 were altered in NSCLC tissues, the present study first detected the expression levels in 26 pairs of NSCLC tissues and paired adjacent normal lung tissues. RT-qPCR analysis revealed that compared with the normal tissues, NSCLC tissues exhibited a significant increase in ANRIL expression and a significant decrease in miR-98 expression (Fig. 1A and B). In addition, Pearson's correlation analysis revealed that the expression of ANRIL was significantly negatively correlated with the expression of miR-98 in lung cancer tissues (Fig. 1C). These results suggested that abnormal expression of ANRIL and miR-98 may serve crucial roles in the development of NSCLC.

ANRIL is upregulated and miR-98 is downregulated in DDP-resistant lung cancer cells. The expression levels of ANRIL and miR-98 in parental lung cancer cells A549 and DDP-resistant A549/DDP cells were assessed by RT-qPCR. Compared with normal lung epithelial cells BEAS-2B, ANRIL expression was significantly increased in A549 cells (Fig. 2A). miR-98 expression was significantly decreased in A549 cells compared with that in BEAS-2B cells (Fig. 2B). Furthermore, ANRIL expression in A549/DDP cells was higher compared with that in their parental A549 cell line (Fig. 2A), and miR-98 expression was lower in A549/DDP cells compared with that in A549 cells (Fig. 2B). These results suggested that ANRIL and miR-98 may be involved in the development of DDP resistance in lung cancer cells.

ANRIL overexpression promotes DDP resistance in lung cancer cells. To determine the functional roles of ANRIL in DDP resistance of lung cancer, ANRIL was overexpressed in A549 cells by transfecting them with pcDNA-ANRIL or an empty control vector. The results of the RT-qPCR analysis revealed that A549 cells transfected with pcDNA-ANRIL exhibited a $>20$-fold increase in ANRIL expression compared with vector-treated cells (Fig. 3A). As presented in Fig. 3B, the MTT assay revealed that DDP administration led to a marked decrease in cell proliferation at 48 and $72 \mathrm{~h}$ in A549 cells, whereas ectopic expression of ANRIL significantly alleviated the inhibitory effects of DDP on cell proliferation at 48 and $72 \mathrm{~h}$. In addition, DDP administration led to a marked decrease in Ki67 expression, and overexpression of ANRIL alleviated the inhibitory effects of DDP on Ki67 expression in A549 cells (Fig. 3C). The results of the present study demonstrated that ANRIL overexpression significantly alleviated the inhibitory effects of DDP on the activation of the MEK/ERK pathway (Fig. 3D). Flow cytometry analysis results demonstrated that DDP treatment induced the apoptosis of A549 cells, whereas overexpression of ANRIL partially impeded the DDP-induced apoptosis in A549 cells compared with that in the vector group (Fig. 3E). In addition, DDP treatment resulted in increased 
A

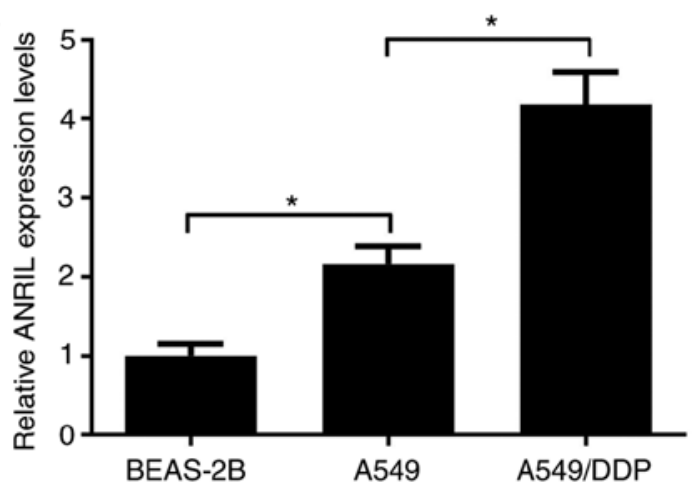

B

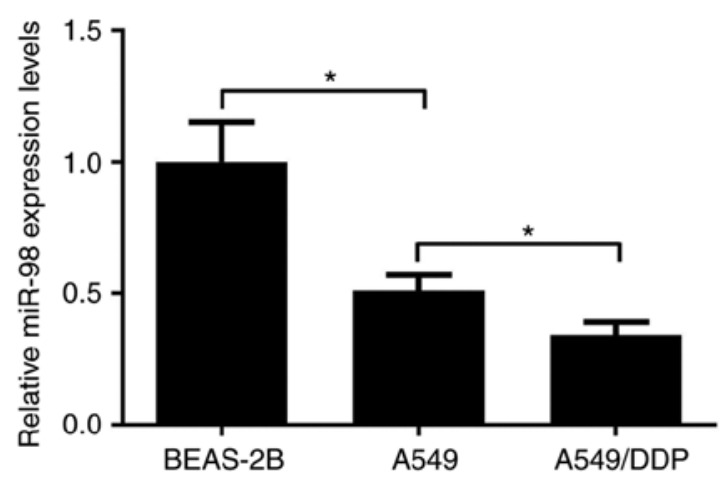

Figure 2. Expression of ANRIL and miR-98 in DDP-resistant lung cancer cells. Reverse transcription-quantitative PCR analysis of (A) ANRIL and (B) miR-98 expression levels in normal lung epithelial cells BEAS-2B, parental A549 cells and DDP-resistant A549/DDP cells. *P<0.05. ANRIL, antisense non-coding RNA in the inhibitor of cyclin-dependent kinase 4 locus; miR, microRNA; DDP, cisplatin.

expression of the apoptosis-associated protein cleaved caspase-3, and ANRIL overexpression partially reversed the promotive effects of DDP on cleaved caspase- 3 expression in A549 cells (Fig. 3F). Collectively, these results demonstrated that ANRIL overexpression increased DDP resistance in lung cancer cells.

ANRIL knockdown inhibits DDP resistance in A549/DDP cells. To further confirm the association between ANRIL and DDP resistance in lung cancer cells, ANRIL-knockdown A549/DDP cells were established by siRNA. As presented in Fig. 4A, si-ANRIL-1, si-ANRIL-2 and si-ANRIL-3 effectively reduced ANRIL expression in A549/DDP cells compared with that in the si-NC group. si-ANRIL-3 exhibited the highest knockdown efficiency and thus was selected for further experiments. MTT assay results revealed that cell proliferation following DDP treatment was repressed at 48 and $72 \mathrm{~h}$ in A549/DDP cells compared with that in the untreated control, and ANRIL knockdown exacerbated the DDP-induced cell proliferation inhibition at 24, 48 and $72 \mathrm{~h}$ (Fig. 4B). In addition, compared with that in the control group, DDP treatment significantly inhibited the expression of Ki67, and ANRIL knockdown significantly enhanced this inhibitory effect in A549/DDP cells (Fig. 4C). Knockdown of ANRIL also promoted the inhibitory effects of DDP on the activation of the MEK/ERK pathway (Fig. 4D). In addition, DDP treatment significantly promoted the apoptosis of A549 cells compared with that in the control group, whereas ANRIL knockdown reinforced the DDP-induced apoptosis, as demonstrated by flow cytometry analysis (Fig. 4E). Additionally, DDP treatment significantly induced the expression of cleaved caspase-3 compared with that in the control group, and ANRIL knockdown enhanced these effects in A549/DDP cells (Fig. 4F). Taken together, these results revealed that ANRIL knockdown significantly inhibited DDP resistance in A549/DDP cells.

ANRIL directly interacts with miR-98 and suppresses miR-98 expression in lung cancer cells. In view of the inverse expression trend of ANRIL and miR-98 in the parental and DDP-resistant lung cancer cells, the present study further investigated the potential interaction between ANRIL and
miR-98. Through bioinformatics online software analyses by miRcode and Starbase 2.0 , the present study discovered that miR-98 contained putative binding sites with ANRIL, as presented in Fig. 5A. The luciferase reporter assay results revealed that miR-98 significantly repressed the luciferase activity in A549 and A549/DDP cells transfected with ANRIL-WT, but did not suppress luciferase activity in A549 and A549/DDP cells transfected with ANRIL-MUT (Fig. 5B), suggesting a direct interaction between miR-98 and ANRIL. To confirm whether ANRIL and miR-98 were in the same RNA-induced silencing complex (RISC), a RIP assay was performed in A549 and A549/DDP cell extracts using an antibody against Ago2, and the immunoprecipitated RNA levels were assessed by RT-qPCR. ANRIL and miR-98 were enriched in the Ago2 pellet in both A549 and A549/DDP cell extracts relative to the control IgG immunoprecipitates (Fig. 5C). In order to further investigate the regulatory effect of ANRIL on miR-98 expression, RT-qPCR was used to evaluate the expression of miR-98 in A549 and A549/DDP cells transfected with pcDNA-ANRIL, si-ANRIL or the respective controls. The results demonstrated that ANRIL knockdown increased, whereas overexpression of ANRIL decreased miR-98 expression in A549 and A549/DDP cells (Fig. 5D). Collectively, these results demonstrated that ANRIL may function as a molecular sponge of miR-98 and inhibit its expression in lung cancer cells.

ANRIL-miR-98 axis participates in the regulation of DDP resistance in DDP-resistant lung cancer cells. Since upregulation of miR-98 was demonstrated to sensitize lung cancer cells to DDP, the present study investigated the functional effects of the ANRIL-miR-98 axis on DDP resistance of lung cancer cells. A549/DDP cells were transfected with miR-98 mimics, and miR-98 expression levels were significantly elevated in the miR-98 transfected A549/DDP cells compared with those in the miR-NC group (Fig. 6A). As presented in Fig. 6B and C, miR-98 mimics promoted the inhibitory effects of DDP on cell proliferation and Ki67 expression in A549/DDP cells, which was partially reversed by overexpression of ANRIL, which was determined by MTT and western blot assays. In addition, miR-98 mimics promoted the inhibitory effects of DDP on the MEK/ERK signaling pathway, which was partially reversed by 

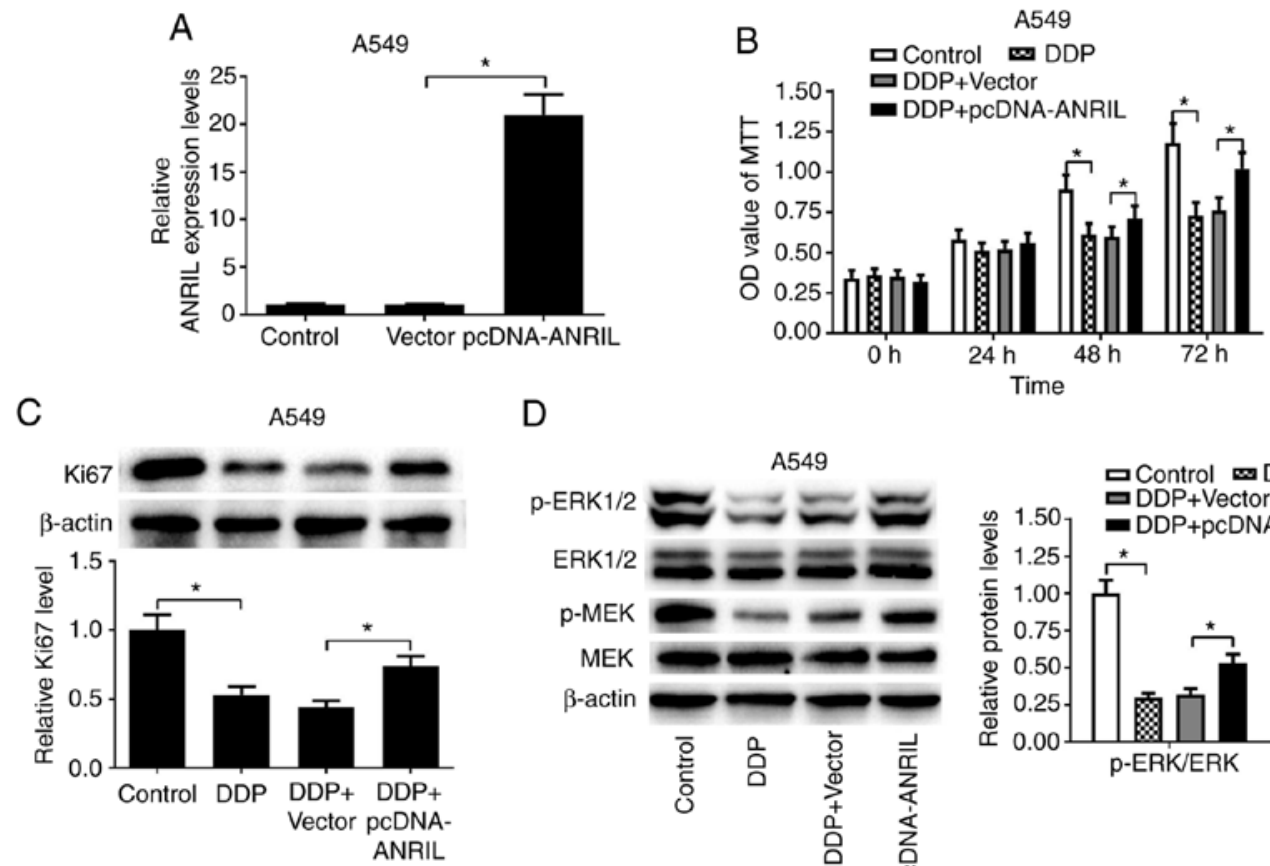

D
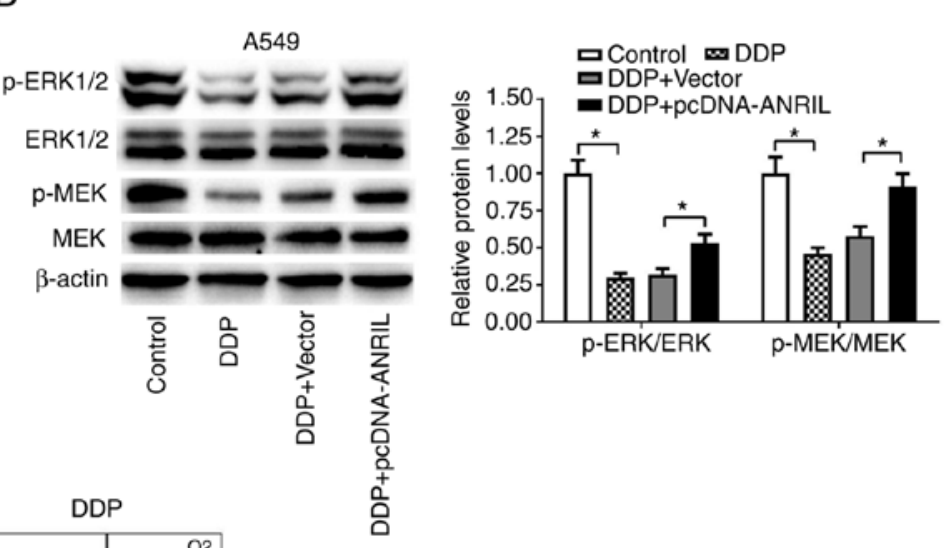

E
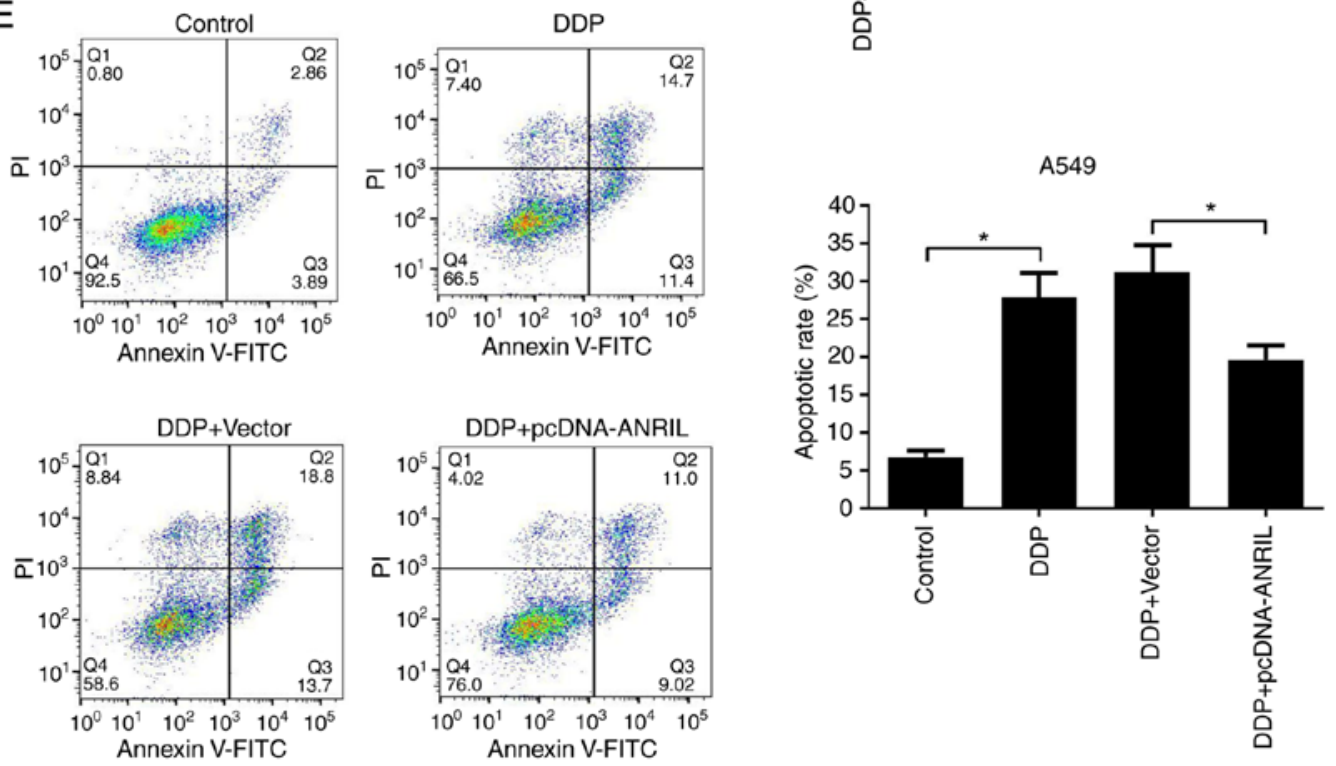

$\mathrm{F}$
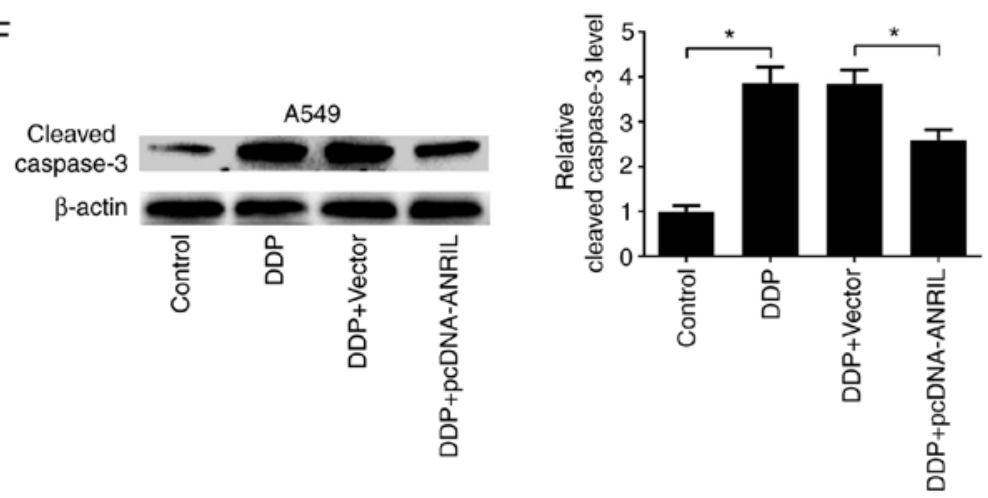

Figure 3. ANRIL overexpression enhances DDP resistance in lung cancer cells. A549 cells were transfected with pcDNA-ANRIL or an empty vector. (A) The expression levels of ANRIL in transfected A549 cells were estimated by reverse transcription-quantitative PCR. (B) MTT assay was performed to detect cell proliferation after the transfected A549 cells were treated with $1 \mu \mathrm{g} / \mathrm{ml}$ DDP for 0, 24, 48 and $72 \mathrm{~h}$. (C and D) Western blotting was performed to assess the expression levels of Ki67, MEK, p-MEK, ERK1/2 and p-ERK1/2 after the transfected A549 cells were exposed to $1 \mu \mathrm{g} / \mathrm{ml}$ DDP for $48 \mathrm{~h}$. (E) Flow cytometry analysis was performed to determine the apoptotic rates after the transfected A549 cells were treated with $1 \mu \mathrm{g} / \mathrm{ml}$ DDP for $48 \mathrm{~h}$. (F) Western blot analysis of the expression of cleaved caspase- 3 was performed after the transfected A549 cells were exposed to $1 \mu \mathrm{g} / \mathrm{ml}$ DDP for $48 \mathrm{~h}$. "P<0.05. ANRIL, antisense non-coding RNA in the inhibitor of cyclin-dependent kinase 4 locus; DDP, cisplatin; ERK, mitogen-activated protein kinase; MEK-mitogen-activated protein kinase kinase; p, phosphorylated; PI, propidium iodide. 
A

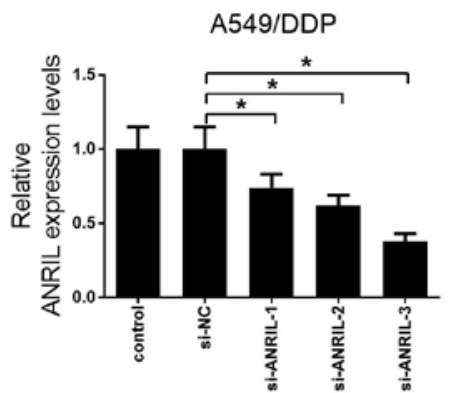

B

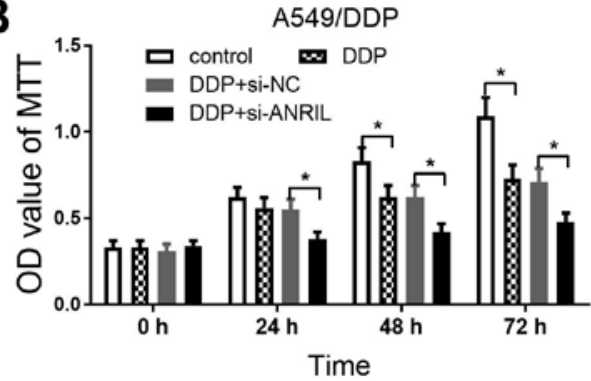

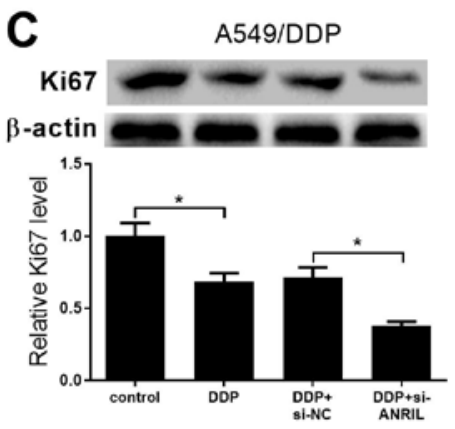

D
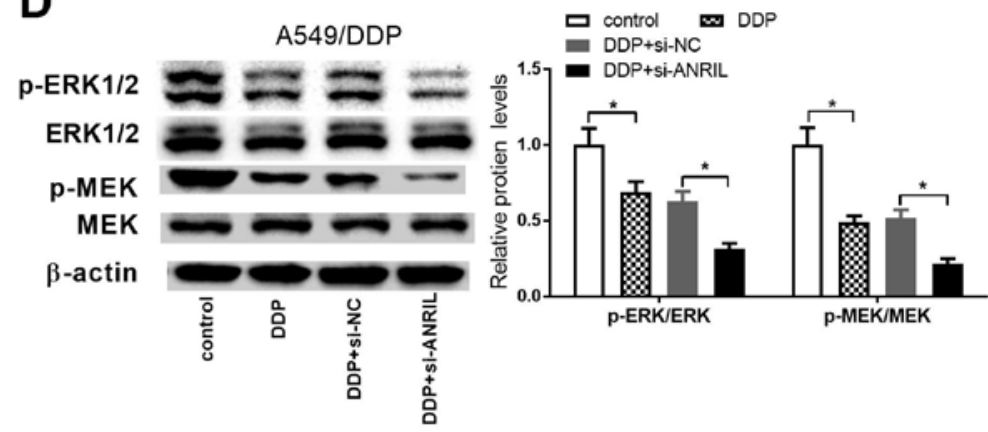

$\mathbf{E}$
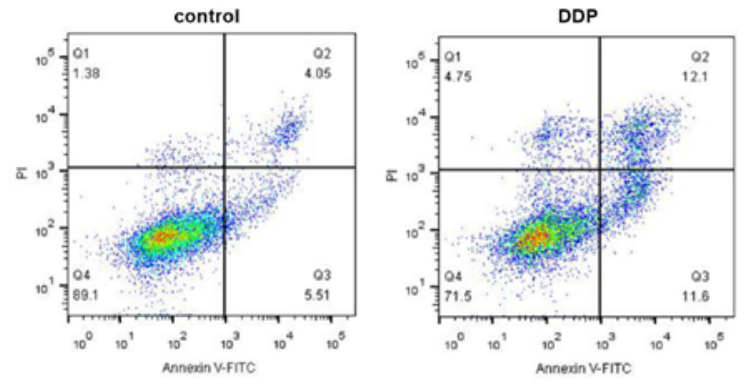

DDP+si-NC

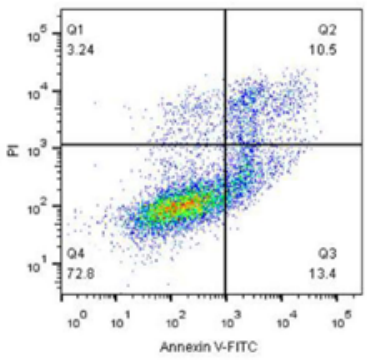

DDP+si-ANRIL
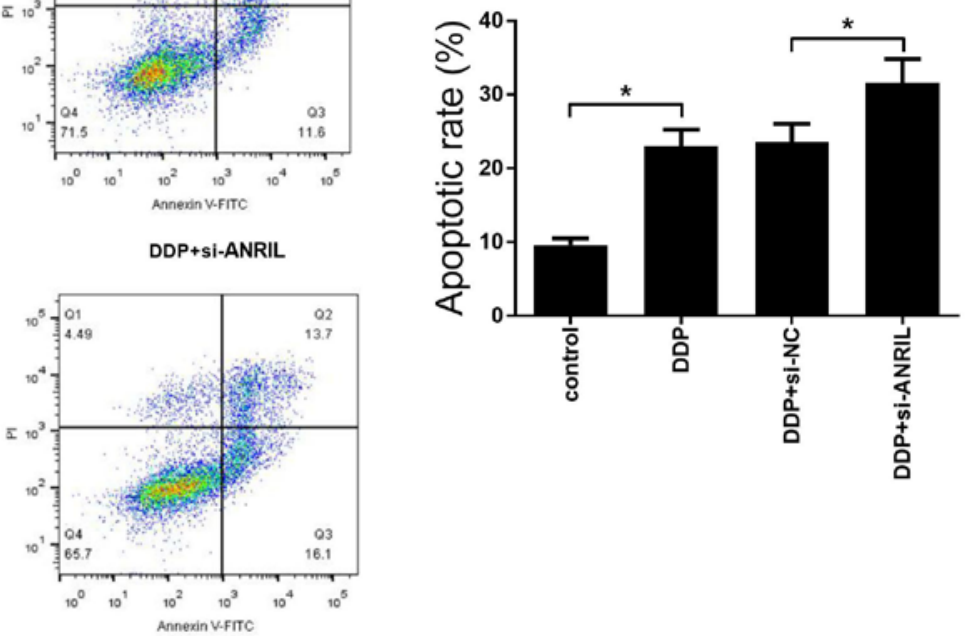

F
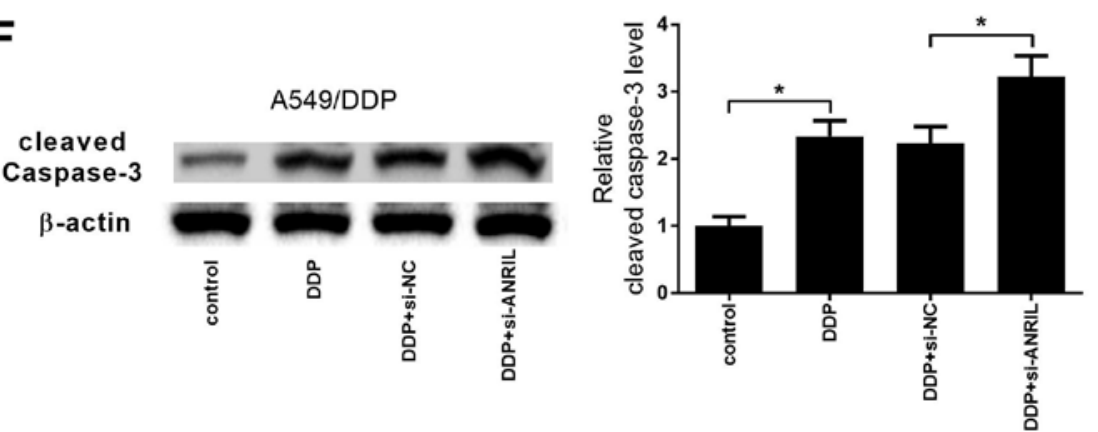

Figure 4. ANRIL knockdown significantly inhibits DDP resistance in A549/DDP cells. (A) The expression of ANRIL in A549/DDP cells transfected with si-NC, si-ANRIL-1, si-ANRIL-2 or si-ANRIL-3 was examined by reverse transcription-quantitative PCR. (B) MTT assay was applied to determine the cell proliferation after A549 cells were transfected with si-ANRIL or si-NC, followed by treatment with $2 \mu \mathrm{g} / \mathrm{ml}$ DDP for 0, 24, 48 and $72 \mathrm{~h}$. (C and D) Western blot analysis of the expression of Ki67, MEK, p-MEK, ERK1/2 and p-ERK1/2 was performed after the transfected A549/DDP cells were exposed to $2 \mu \mathrm{g} / \mathrm{ml}$ DDP for $48 \mathrm{~h}$. (E) Flow cytometry analysis was conducted to detect apoptosis after si-ANRIL- or si-NC-transfected A549/DDP cells were treated with $2 \mu \mathrm{g} / \mathrm{ml}$ DDP for $48 \mathrm{~h}$. (F) Western blot analysis of the expression of cleaved caspase-3 was performed after the transfected A549/DDP cells were exposed to $2 \mu \mathrm{g} / \mathrm{ml}$ DDP for $48 \mathrm{~h}$. "P<0.05. ANRIL, antisense non-coding RNA in the inhibitor of cyclin-dependent kinase 4 locus; siRNA, small interfering RNA; NC, negative control; DDP, cisplatin; ERK, mitogen-activated protein kinase; MEK-mitogen-activated protein kinase kinase; p, phosphorylated; PI, propidium iodide. 
A
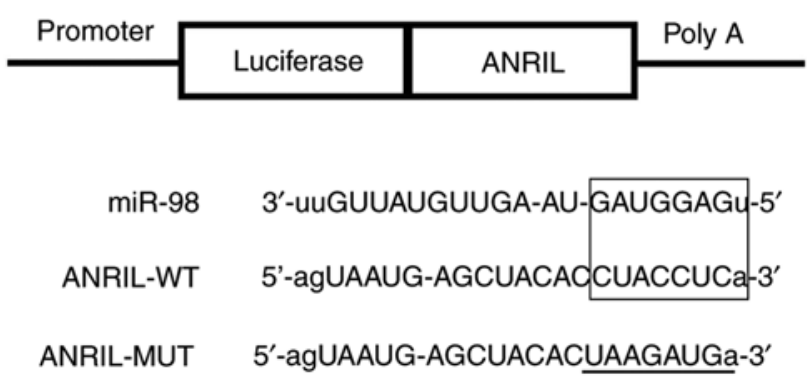

C

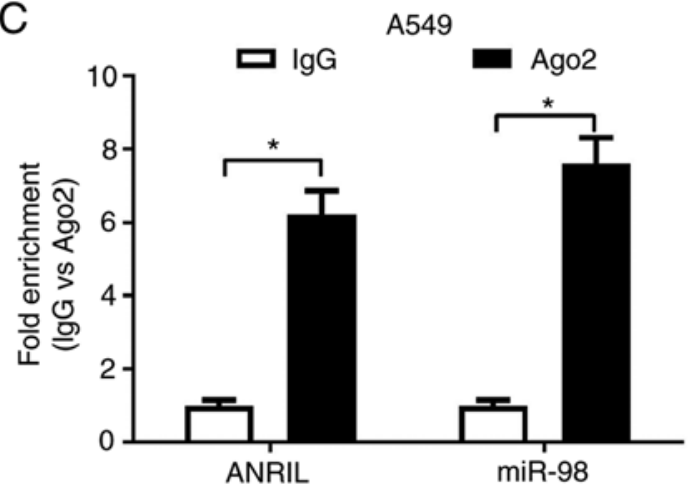

D

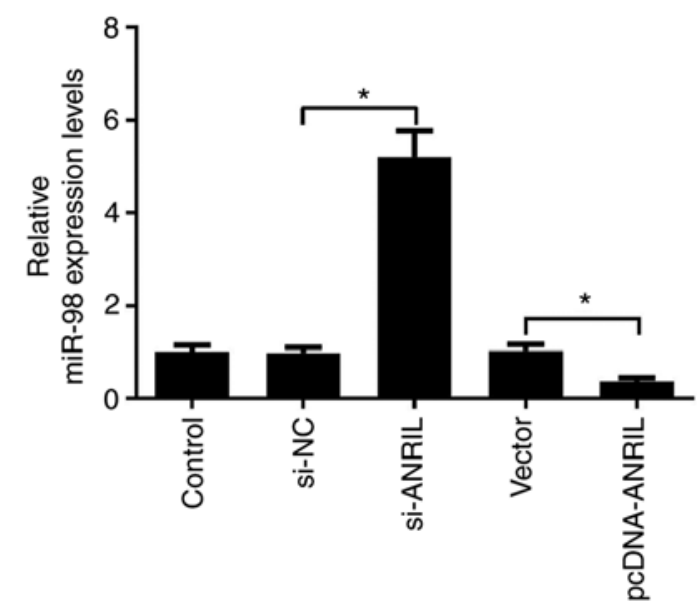

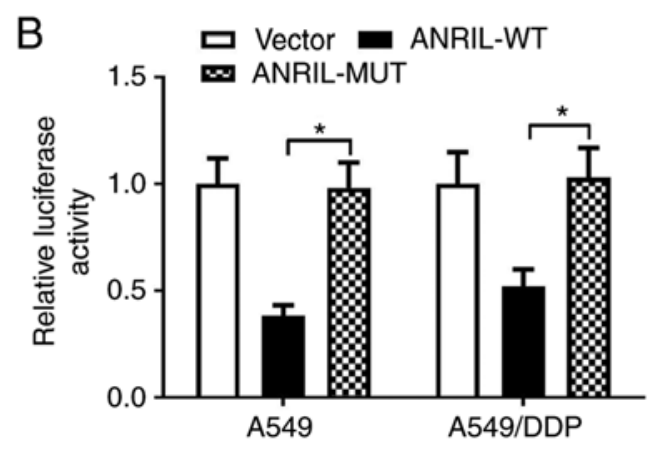
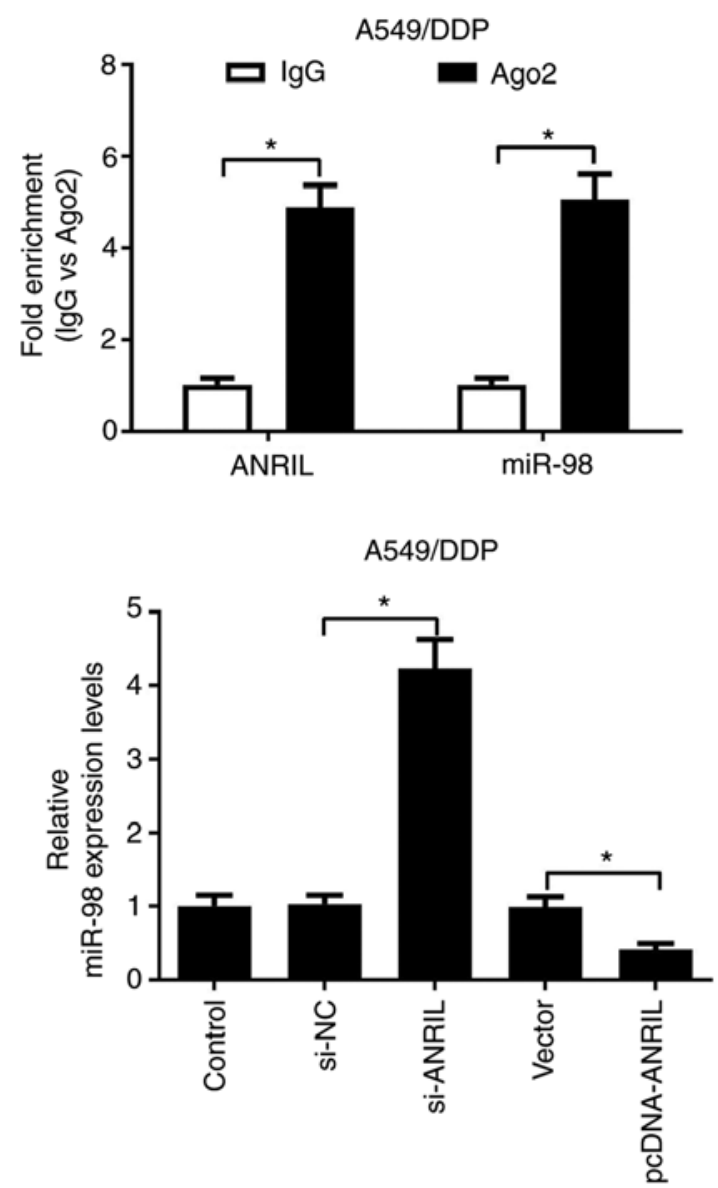

Figure 5. ANRIL directly interacts with miR-98 and suppresses miR-98 expression in lung cancer cells. (A) The predicted miR-98 binding sites in ANRIL-WT or ANRIL-MUT are indicated. (B) A549 and A549/DDP cells were co-transfected with miR-98 mimics and the vector, ANRIL-WT or ANRIL-MUT. Luciferase reporter assay was performed to measure luciferase activities at $48 \mathrm{~h}$ post-transfection. (C) Radioimmunoprecipitation assay was performed in A549 and A549/DDP cell extracts using an antibody against Ago2. The immunoprecipitated RNA levels were assessed by RT-qPCR. (D) The expression levels of miR-98 were determined by RT-qPCR in A549 and A549/DDP cells transfected with pcDNA-ANRIL, si-ANRIL or the respective controls. "P<0.05. ANRIL, antisense non-coding RNA in the inhibitor of cyclin-dependent kinase 4 locus; miR, microRNA; DDP, cisplatin; WT, wild-type; MUT, mutant; Ago2, argonaute 2; RT-qPCR, reverse transcription-quantitative PCR.

ANRIL overexpression (Fig. 6D). Additionally, flow cytometry analysis results demonstrated that miR-98 mimics significantly enhanced the DDP-induced apoptosis of A549/DDP cells, whereas ANRIL overexpression abolished the promotive effect of miR-98 on the DDP-induced apoptosis (Fig. 7A). Furthermore, cleaved caspase-3 expression was upregulated in A549/DDP cells transfected with miR-98 mimics, and ANRIL overexpression partially inversed this phenomenon (Fig. 7B). Therefore, the present study concluded that ANRIL overexpression reversed miR-98 overexpression-mediated DDP resistance repression in DDP-resistant lung cancer cells.

\section{Discussion}

Accumulating evidence has demonstrated that dysregulated lncRNAs are involved in various aspects of cancer biology and serve functional roles in the development of drug resistance in numerous types of cancer, including lung cancer $(23,24)$. For example, lncRNA regulator of reprogramming (ROR) has been demonstrated to be expressed at high levels in A549/DDP cells, and ROR silencing improves the sensitivity of NSCLC to DDP by inhibiting the PI3K/Akt/mTOR signaling pathway (25). In addition, IncRNA HOTAIR has been demonstrated to be 
A

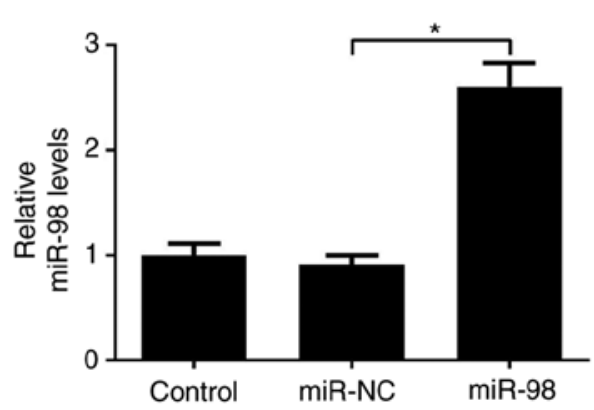

$\mathrm{C}$

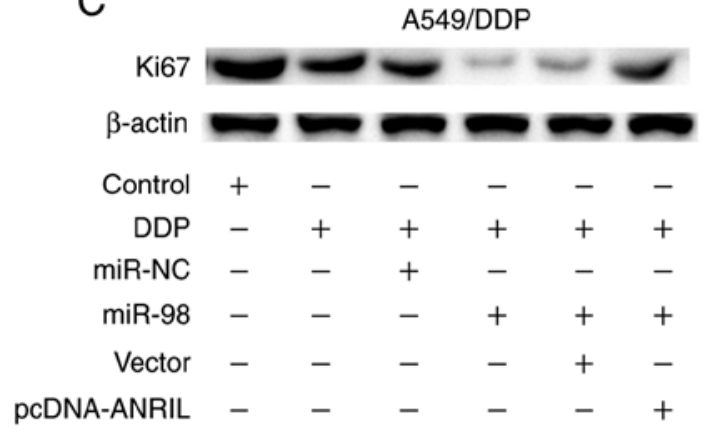

B $\quad$-Control $m$ DDP $=D D P+m i R-N C$
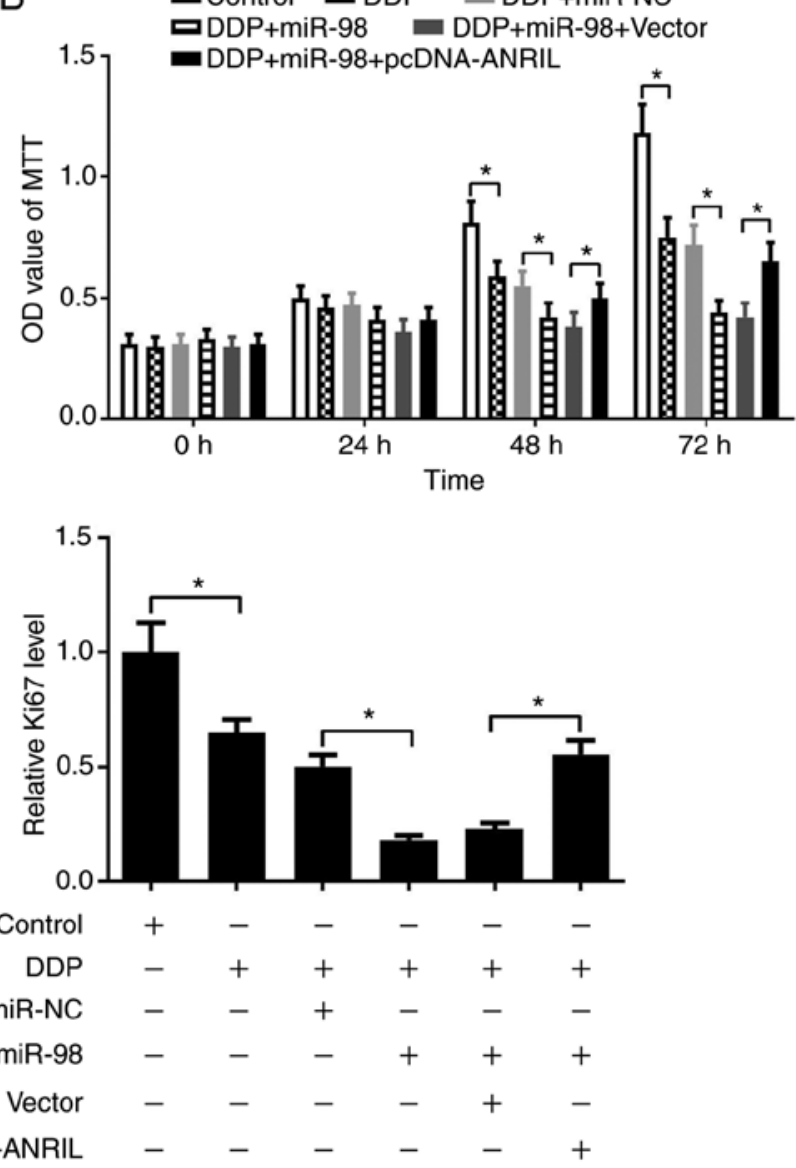

pcDNA-ANRIL $\quad-\quad-\quad-\quad-\quad-\quad+$

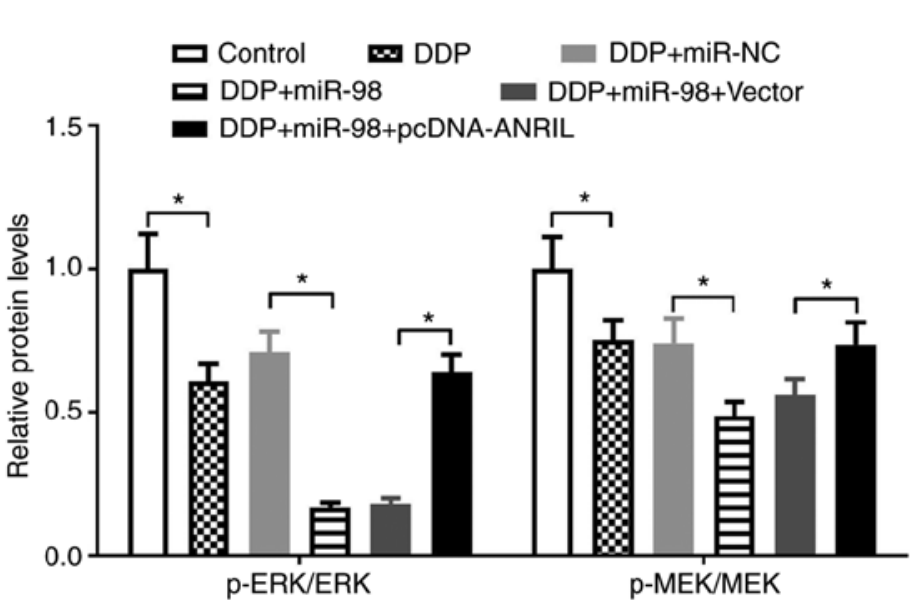

Figure 6. ANRIL-miR-98 axis regulates DDP resistance in DDP-resistant lung cancer cells by modulating cell proliferation. A549/DDP cells were transfected with miR-NC, miR-98 or combined with the vector or pcDNA-ANRIL and cultured for $48 \mathrm{~h}$. (A) The expression of miR-98 was determined by reverse transcription-quantitative PCR in A549/DDP cells transfected with miR-NC or miR-98 at 48 h. (B) Cell proliferation was determined by MTT assay in transfected A549/DDP cells following $2 \mu \mathrm{g} / \mathrm{ml}$ DDP treatment for 0,24, 48 or $72 \mathrm{~h}$. (C and D) Western blotting was used to detect the expression levels of Ki67, MEK, p-MEK, ERK1/2 and p-ERK1/2 in the transfected A549/DDP cells treated with or without $2 \mu \mathrm{g} / \mathrm{ml}$ DDP for $48 \mathrm{~h}$. "P<0.05. ANRIL, antisense non-coding RNA in the inhibitor of cyclin-dependent kinase 4 locus; miR, microRNA; NC, negative control; DDP, cisplatin; ERK, mitogen-activated protein kinase; MEK-mitogen-activated protein kinase kinase; $p$, phosphorylated.

aberrantly upregulated in A549/DDP cells, and inhibition of HOTAIR expression increases the sensitivity of A549/DDP cells to DDP (26). LncRNA maternally expressed gene 3 (Meg3) is revealed to be downregulated in A549/DDP cells and enhance DDP resistance in lung cancer cells through the activation of the WNT//-catenin signaling pathway (27). However, the potential function of ANRIL in regulating DDP resistance in lung cancer remains unclear.
An increasing amount of evidence has reported that ANRIL is deregulated and exerts oncogenic activities in the tumorigenesis and drug resistance of several types of cancer. For instance, ANRIL has been demonstrated to be upregulated in nasopharyngeal carcinoma (NPC) cells; knockdown of ANRIL represses the proliferation, promotes the apoptosis, improves the radiosensitivity and enhances the DDP-induced cytotoxicity in NPC cells $(28,29)$. ANRIL is highly expressed in gastric cancer 
A
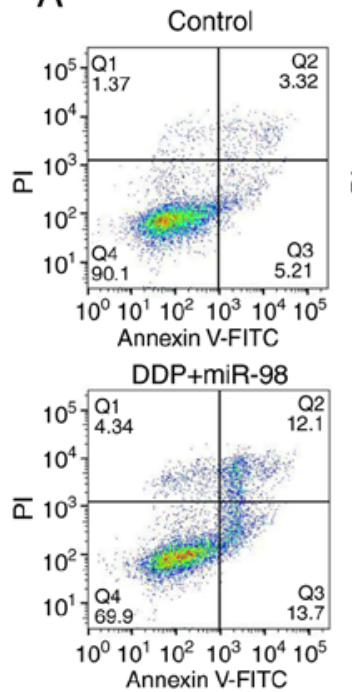

A549/DDP
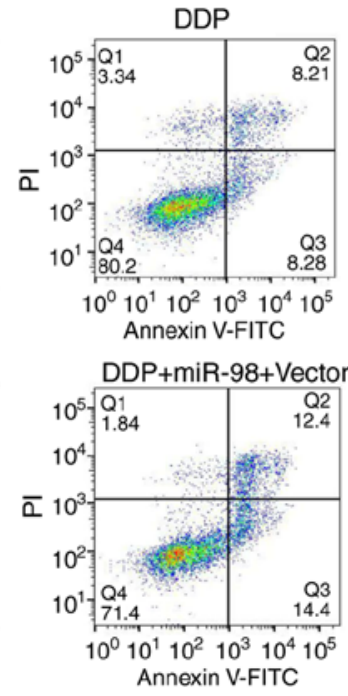

B

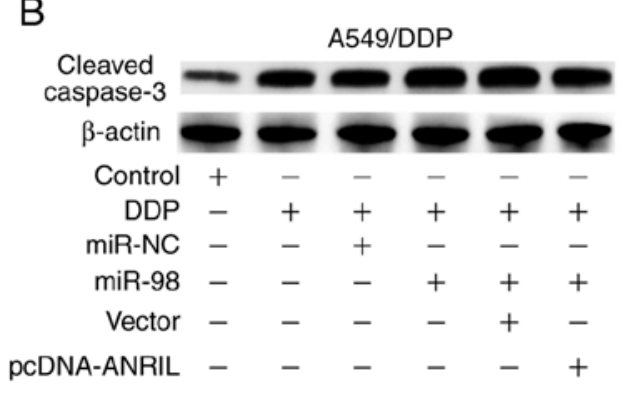

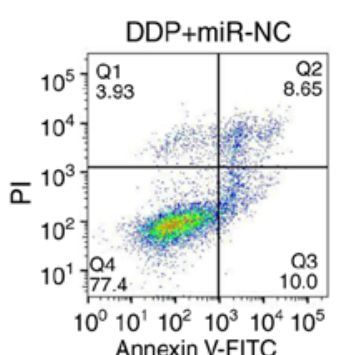

Annexin V-FITC

DDP+miR-98+pcDNA-ANRIL

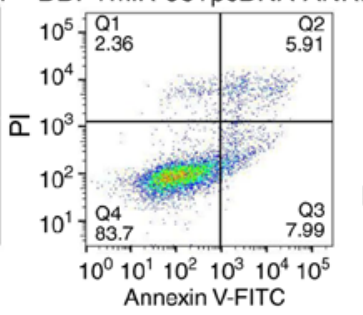

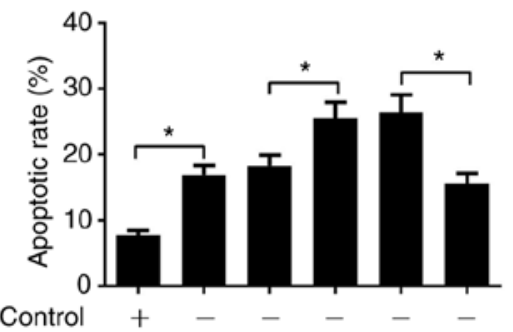

DDP -++++

miR-NC - $-+-\quad-$

miR-98 - --+++

Vector - $-\quad-\quad-\quad+-$

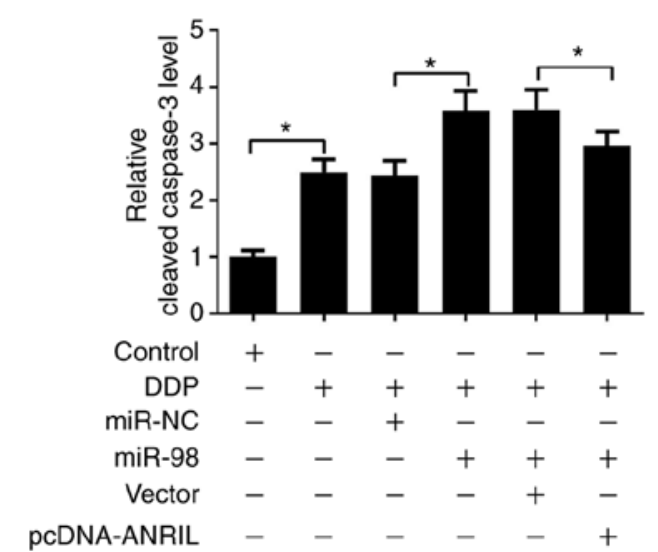

Figure 7. ANRIL-miR-98 axis regulates DDP resistance in DDP-resistant lung cancer cells by modulating apoptosis. A549/DDP cells were transfected with miR-NC, miR-98 or combined with the vector or pcDNA-ANRIL and cultured for 48 h. (A) Apoptosis was detected by flow cytometry analysis after transfected A549/DDP cells were exposed to $2 \mu \mathrm{g} / \mathrm{ml}$ DDP for $48 \mathrm{~h}$. (B) Western blot analysis of the expression of cleaved caspase-3 was performed on the treated A549/DDP cells. ${ }^{*} \mathrm{P}<0.05$. ANRIL, antisense non-coding RNA in the inhibitor of cyclin-dependent kinase 4 locus; miR, microRNA; NC, negative control; DDP, cisplatin.

tissues from DDP- and 5-fluorouracil (5-FU)-resistant patients, and knockdown of ANRIL in gastric cancer cells inhibits the development of multidrug resistance (30). The results of the present study demonstrated that ANRIL was upregulated in lung cancer tissues and A549/DDP cells compared with normal lung tissues and cells. Functional analyses demonstrated that ANRIL overexpression reversed the DDP-induced suppression of cell proliferation and apoptosis, whereas ANRIL knockdown exhibited the opposite effects, suggesting that ANRIL participated in the development of DDP resistance in lung cancer cells. Similarly, a previous study has demonstrated that ANRIL functions as a potential oncogene as it is upregulated and promotes the acquisition of paclitaxel resistance in lung adenocarcinoma A549 cells (31).

Although in the present study ANRIL was demonstrated to be involved in DDP resistance of lung cancer cells, the underlying mechanism remains to be further elucidated. It has been reported that miRNAs exert their function through the RISC that contains Ago2 (32). A ceRNA regulatory hypothesis has been proposed, which suggests that IncRNAs serve an important role in multiple processes of cancer cells by functioning as endogenous miRNA sponges and regulating
miRNA expression and biological functions (33). For example, a lncRNA termed upregulated in CRC may act as an endogenous sponge by competing for miR-143 to regulate the targets of this miRNA, therefore promoting colorectal cancer progression (34). LncRNA urothelial carcinoma-associated 1 enhances the cell proliferation and 5-FU resistance in colorectal cancer by sponging endogenous miR-204-5p (32). ANRIL acts as a molecular sponge of miR-186 to contribute to cervical cancer tumorigenesis (35). In pediatric medulloblastoma, ANRIL inhibition represses cell proliferation and migration, but promotes apoptosis by acting as a molecular sponge of miR-323 (36). In addition, ANRIL knockdown represses tumorigenicity and enhances DDP sensitivity in NPC cells by negatively regulating miRNA let-7a (37). The results of the present study demonstrated that in NSCLC tissues, there was a significant upregulation in ANRIL expression and downregulation in miR-98 expression compared with those in adjacent normal tissues. Of note, ANRIL expression exhibited a significant negative correlation with that of miR-98 in lung cancer tissues. In order to improve the current understanding of the underlying mechanism of the lncRNA/miRNA regulatory function, the present study performed RIP assay, luciferase reporter assay 
and RT-qPCR analysis, and demonstrated that ANRIL functioned as a molecular sponge of miR-98 in lung cancer cells. In accordance with a previous study (20), the present study confirmed that miR-98 was downregulated in A549/DDP cells, and miR-98 mimics promoted the DDP-induced cell proliferation inhibition and apoptosis of A549/DDP cells. Certain studies have reported that the MEK/ERK signaling pathway is involved in the progression and drug resistance of multiple types of cancer $(29,38)$. In the present study, the phosphorylation levels of MEK and ERK were reduced by DDP treatment in lung cancer cells, and ANRIL negatively regulated the miR-98 mimic-induced repression on the MEK/ERK signaling pathway. Mechanistic analyses further revealed that overexpression of ANRIL reversed the miR-98 mimic-induced suppression of DDP resistance in lung cancer cells, indicating that ANRIL regulated the development of DDP resistance by functioning as a ceRNA of miR-98.

In the present study, due to the limitation of the conditions, the animal experiments to confirm the results in vivo have not been performed. These experiments will be performed in our future study.

In summary, the present study demonstrated the upregulation of ANRIL and downregulation of miR-98 in lung cancer tissues and DDP-resistant lung cancer cells compared with normal lung tissues and cells. Functional and mechanistic analyses demonstrated that ANRIL knockdown inhibited the development of DDP resistance by functioning as a ceRNA of miR-98, providing novel insights into the molecular mechanism of ANRIL involved in the DDP resistance of lung cancer cells. The present study reported that ANRIL may be a novel potential therapeutic target to overcome DDP resistance in lung cancer.

\section{Acknowledgements}

Not applicable.

\section{Funding}

No funding was received.

\section{Availability of data and materials}

The datasets generated and/or analyzed during the current study are available from the corresponding author on reasonable request.

\section{Authors' contributions}

XW, GZ, ZC, LD and ML designed the study, performed the experiments and drafted the manuscript. XJ, HW and RZ analyzed the data and revised the manuscript. TJ, YY, LJ and MY provided technical support and revised the manuscript. All authors read and approved the final manuscript.

\section{Ethics approval and consent to participate}

The present study was reviewed and approved by the Research Ethics Committee of the First Affiliated Hospital of Zhengzhou University. Written consent was obtained from all patients.

\section{Patient consent for publication}

Not applicable.

\section{Competing interests}

The authors declare that they have no competing interests.

\section{References}

1. Riaz MK, Zhang X, Wong KH, Chen H, Liu Q, Chen X, Zhang G, Lu A and Yang Z: Pulmonary delivery of transferrin receptors targeting peptide surface-functionalized liposomes augments the chemotherapeutic effect of quercetin in lung cancer therapy. Int J Nanomedicine 14: 2879-2902, 2019.

2. Romero-Vielva L, Viteri S, Moya-Horno I, Toscas JI, Maestre-Alcácer JA, Ramón Y, Cajal S and Rosell R: Salvage surgery after definitive chemo-radiotherapy for patients with non-Small cell lung cancer. Lung Cancer 133: 117-122, 2019.

3. Chen QY, Jiao DM, Wang J, Hu H, Tang X, Chen J, Mou H and Lu W: miR-206 regulates cisplatin resistance and EMT in human lung adenocarcinoma cells partly by targeting MET. Oncotarget 7: 24510-24526, 2016.

4. Guo L, Song P, Xue X, Guo C, Han L, Fang Q, Ying J, Gao S and $\mathrm{Li} \mathrm{W}$ : Variation of programmed death ligand 1 expression after platinum-based neoadjuvant chemotherapy in lung cancer. J Immunother 42: 215-220, 2019.

5. Yang Q, Zhang Z, Xu H and Ma C: Lidocaine alleviates cytotoxicity-resistance in lung cancer A549/DDP cells via down-regulation of miR-21. Mol Cell Biochem 456: 63-72, 2019.

6. Djebali S, Davis CA, Merkel A, Dobin A, Lassmann T, Mortazavi A, Tanzer A, Lagarde J, Lin W, Schlesinger F, et al: Landscape of transcription in human cells. Nature 489: 101-108, 2012.

7. Martens-Uzunova ES, Böttcher R, Croce CM, Jenster G, Visakorpi T and Calin GA: Long noncoding RNA in prostate, bladder, and kidney cancer. Eur Urol 65: 1140-1151, 2014.

8. Pan JJ, Xie XJ, Li X and Chen W: Long non-coding RNAs and drug resistance. Asian Pac J Cancer Prev 16: 8067-8073, 2015.

9. Zhang Z, Zhu Z, Watabe K, Zhang X, Bai C, Xu M, Wu F and Mo YY: Negative regulation of lncRNA GAS5 by miR-21. Cell Death Differ 20: 1558-1568, 2013.

10. Tano $\mathrm{K}$ and Akimitsu N: Long non-coding RNAs in cancer progression. Front Genet 3: 219, 2012.

11. Zhang EB, Kong R, Yin DD, You LH, Sun M, Han L, Xu TP, Xia R, Yang JS, De W and Chen Jf: Long noncoding RNA ANRIL indicates a poor prognosis of gastric cancer and promotes tumor growth by epigenetically silencing of miR-99a/miR-449a. Oncotarget 5: 2276-2292, 2014.

12. Nie FQ, Sun M, Yang JS, Xie M, Xu TP, Xia R, Liu YW, Liu XH, Zhang EB, Lu K and Shu YQ: Long noncoding RNA ANRIL promotes non-small cell lung cancer cell proliferation and inhibits apoptosis by silencing KLF2 and P21 expression. Mol Cancer Ther 14: 268-277, 2015.

13. Iranpour M, Soudyab M, Geranpayeh L, Mirfakhraie R, Azargashb E, Movafagh A and Ghafouri-Fard S: Expression analysis of four long noncoding RNAs in breast cancer. Tumour Biol 37: 2933-2940, 2016.

14. Wan G, Mathur R, Hu X, Liu Y, Zhang X, Peng G and Lu X: Long non-coding RNA ANRIL (CDKN2B-AS) is induced by the ATM-E2F1 signaling pathway. Cell Signal 25: 1086-1095, 2013.

15. Bartel DP: MicroRNAs: Genomics, biogenesis, mechanism, and function. Cell 116: 281-297, 2004.

16. Xu P, Guo M and Hay BA: MicroRNAs and the regulation of cell death. Trends Genet 20: 617-624, 2004.

17. Cheng AM, Byrom MW, Shelton J and Ford LP: Antisense inhibition of human miRNAs and indications for an involvement of miRNA in cell growth and apoptosis. Nucleic Acids Res 33: 1290-1297, 2005.

18. Ma J, Dong C and Ji C: MicroRNA and drug resistance. Cancer Gene Ther 17: 523-531, 2010.

19. MacDonagh L, Gray SG, Finn SP, Cuffe S, O'Byrne KJ and Barr MP: The emerging role of microRNAs in resistance to lung cancer treatments. Cancer Treat Rev 41: 160-169, 2015.

20. Xiang Q, Tang H, Yu J, Yin J, Yang X and Lei X: MicroRNA-98 sensitizes cisplatin-resistant human lung adenocarcinoma cells by up-regulation of HMGA2. Pharmazie 68: 274-281, 2013. 
21. Ren K, Li Y, Lu H, Li Z, Li Z, Wu K, Li Z and Han X: Long noncoding RNA HOTAIR controls cell cycle by functioning as a competing endogenous RNA in esophageal squamous cell carcinoma. Transl Oncol 9: 489-497, 2016.

22. Livak KJ and Schmittgen TD: Analysis of relative gene expression data using real-time quantitative PCR and the 2(-Delta Delta C(T)) method. Methods 25: 402-408, 2001.

23. Xia $\mathrm{H}$ and Hui KM: Mechanism of cancer drug resistance and the involvement of noncoding RNAs. Curr Med Chem 21 : 3029-3041, 2014.

24. Chen QN, Wei CC, Wang ZX and Sun M: Long non-coding RNAs in anti-cancer drug resistance. Oncotarget 8: 1925-1936, 2017.

25. Shi $\mathrm{H}, \mathrm{Pu}$ J, Zhou XL, Ning YY and Bai C: Silencing long non-coding RNA ROR improves sensitivity of non-small-cel lung cancer to cisplatin resistance by inhibiting PI3K/Akt/mTOR signaling pathway. Tumour Biol 39: 1010428317697568, 2017.

26. Liu MY, Li XQ, Gao TH, Cui Y, Ma N, Zhou Y and Zhang GJ Elevated HOTAIR expression associated with cisplatin resistance in non-small cell lung cancer patients. J Thorac Dis 8 : 3314-3322, 2016

27. Xia Y, He Z, Liu B, Wang P and Chen Y: Downregulation of Meg3 enhances cisplatin resistance of lung cancer cells through activation of the WNT/ $\beta$-catenin signaling pathway. Mol Med Rep 12: 4530-4537, 2015

28. Hu X, Jiang H and Jiang X: Downregulation of lncRNA ANRIL inhibits proliferation, induces apoptosis, and enhances radiosensitivity in nasopharyngeal carcinoma cells through regulating miR-125a. Cancer Biol Ther 18: 331-338, 2017.

29. Wang Y, Cheng N and Luo J: Downregulation of lncRNA ANRIL represses tumorigenicity and enhances cisplatin-induced cytotoxicity via regulating microRNA let-7a in nasopharyngeal carcinoma. J Biochem Mol Toxicol 31: e21904, 2017.

30. Lan WG, Xu DH, Xu C, Ding CL, Ning FL, Zhou YL, Ma LB, Liu CM and Han X: Silencing of long non-coding RNA ANRIL inhibits the development of multidrug resistance in gastric cancer cells. Oncol Rep 36: 263-270, 2016.
31. Xu R, Mao Y, Chen K, He W, Shi W and Han Y: The long noncoding RNA ANRIL acts as an oncogene and contributes to paclitaxel resistance of lung adenocarcinoma A549 cells. Oncotarget 8: 39177-39184, 2017.

32. Bian Z, Jin L, Zhang J, Yin Y, Quan C, Hu Y, Feng Y, Liu H, Fei B, Mao Y, et al: LncRNA-UCA1 enhances cell proliferation and 5-fluorouracil resistance in colorectal cancer by inhibiting miR-204-5p. Sci Rep 6: 23892, 2016.

33. Tay Y, Rinn J and Pandolfi PP: The multilayered complexity of ceRNA crosstalk and competition. Nature 505: 344-352, 2014.

34. Huang FT, Chen WY, Gu ZQ, Zhuang YY, Li CQ, Wang LY, Peng JF, Zhu Z, Luo X, Li YH, et al: The novel long intergenic noncoding RNA UCC promotes colorectal cancer progression by sponging miR-143. Cell Death Dis 8: e2778, 2017.

35. Zhang JJ, Wang DD, Du CX and Wang Y: Long noncoding RNA ANRIL promotes cervical cancer development by acting as a sponge of miR-186. Oncol Res 26: 345-352, 2018.

36. Zhang $\mathrm{H}$, Wang $\mathrm{X}$ and Chen $\mathrm{X}$ : Potential role of long non-coding RNA ANRIL in pediatric medulloblastoma through promotion on proliferation and migration by targeting miR-323. J Cell Biochem 118: 4735-4744, 2017.

37. Nickols NG, Nazarian R, Zhao SG, Tan V, Uzunangelov V, Xia Z, Baertsch R, Neeman E, Gao AC, Thomas GV, et al: MEK-ERK signaling is a therapeutic target in metastatic castration resistant prostate cancer. Prostate Cancer Prostatic Dis 22: 531-538, 2019.

38. Li Q, Wang C, Wang Y, Sun L, Liu Z, Wang L, Song T, Yao Y, Liu Q and Tu K: HSCs-derived COMP drives hepatocellular carcinoma progression by activating MEK/ERK and PI3K/AKT signaling pathways. J Exp Clin Cancer Res 37: 231-231, 2018.

39. Shroff GS, Viswanathan C, Carter BW, Benveniste MF, Truong MT and Sabloff BS: Staging lung cancer: Metastasis. Radiol Clin North Am 56: 411-418, 2018. 